\section{AB1401-HPR SELF-REPORTED PHYSICAL FUNCTION AND ASSOCIATED FACTORS IN INDIVIDUALS WITH SYSTEMIC LUPUS ERYTHEMATOSUS}

Gizem Irem Kinikli ${ }^{1}$, Susanne Petterssonn ${ }^{2}$, Sevilay Karahan ${ }^{3}$, Elisabet Svenungsson ${ }^{4}$, Carina Boström ${ }^{5} .{ }^{1}$ Hacettepe University, Faculty of Physical Therapy and Rehabilitation, Ankara, Turkey, ${ }^{2}$ Karolinska Institutet, Inflammation and Infection Theme, Karolinska University Hospital and Department of Neurobiology, care sciences and society, Stockholm, Sweden; ${ }^{3}$ Hacettepe University, Faculty of Medicine, Department of Biostatistics, Ankara, Turkey; ${ }^{4}$ Karolinska University Hospital, Unit of Rheumatology, Department of Medicine, Stockholm, Sweden; ${ }^{5}$ Karolinska Institutet, Department of Neurobiology, care sciences and society, Stockholm, Sweden

Background: Physical activity and exercise have many positive effects in patients with Systemic Lupus Erythematosus (SLE) (1) and poor selfreported physical function has been reported to predict mortality (2). To facilitate and improve physical activity/function, it is thus important to investigate what factors are associated with good physical function. Few previous studies have addressed these issues (3).

Objectives: The aim of this study was to identify factors associated with good self-reported physical function, such as walking and running in individuals with SLE.

Methods: A total of 198 patients (mean age: 51.516 .1 years; BMI: $24.74 .7 \mathrm{~kg} / \mathrm{m}^{2}$ ) with SLE participated. The outcome, self-reported physical function was assessed with the question: How much do you think you can manage concerning walk, jog, and run? (From Physical Activity Questionnaire, PAQ). Disease activity was assessed using the SLAM-R and organ damage with SLICC/ACR-DI. The VAS part of EQ-5D, was used to assess self-reported health related quality of life (HRQL). Hospital Anxiety and Depression Scale (HADS) was used to assess anxiety/ depression levels. Self-reported exercise during the last year was assessed by questions from PAQ and sitting hours as well as physical activity level was determined from International Physical Activity Questionnaire Short Form (IPAQ-SF). Logistic regression analyses estimated the associations of the following independent variables: age, sex, BMI, disease activity, organ damage, HRQL and anxiety/depression levels, exercise last year, sitting hours and physical activity level, on the dependent variable self-reported physical function (PAQ-question). Statistical significance was defined as a $p$ value $<0.05$.

Results: Median SLAM-R was 6 (IQR:6), SLICC-DI was 1 (IQR:3), EQ5D VAS was 72.2 (IQR:22.1) and depression level 4 (IQR:5). Median Self-reported exercise during the last year (PAQ) was exercise irregularly. Median sitting hours a day (IPAQ-SF) was $<5$ hours. Median physical activity level was moderate (IPAQ-SF). Age $(p<0.001$; Odds ratio:6.40), SLICC-DI ( $p=0.002$; Odds ratio:4.02) and EQ-5D VAS ( $p<0.001$; Odds ratio:4.20) were significantly associated with better self-reported physical function (Nagelkerke R Square $=0.437$ ).

Conclusion: The results demonstrated that SLE-patients who report low physical function are older patients with more organ damage. However, patients who reported low HRQL also reported low physical function. Our results imply that patients with low self-reported $H R Q L$ are at risk for not being enough physically active. To break this vicious circle is a challenge for physicians and physical therapists that care for patients with SLE.

\section{REFERENCES}

[1] O'Dwyer T, Durcan L, Wilson F. Exercise and physical activity in systemic lupus erythematosus: A systematic review with meta-analyses. Semin Arthritis Rheum. 2017;47:204-215.

[2] Azizoddin DR, Jolly M, Arora S, Yelin E, Katz P. Patient Reported Outcomes Predict Mortality in Lupus. Arthritis Care Res (Hoboken). 2018 Aug 24. doi: $10.1002 /$ acr.23734.

[3] Elera-Fitzcarrald C, Fuentes A, Gonzlez LA, Burgos PI, Alarcn GS, Ugarte-Gil MF. Factors affecting quality of life in patients with systemic lupus erythematosus: important considerations and potential interventions. Expert Rev Clin Immunol. 2018;14:915-931.

Disclosure of Interests: None declared

DOI: 10.1136/annrheumdis-2019-eular.6608

\section{AB1402-HPR CHILDRENS COMFORT COUNTS - CHILDREN WITH JUVENILE IDIOPATHIC ARTHRITISEXPERIENCE OF USING ENTONOX AS AN ANALGESIC AGENT FOR INTRA-ARTICULAR JOINT INJECTIONS}

Norma O'Keeffe ${ }^{1}$, Clodagh Lowry ${ }^{1}$, Veronica Lambert ${ }^{2}$, Maeve Muldoon ${ }^{1} .{ }^{1} T e m p l e$ Street Children's University Hospital., Paediatric Rheumatology Department, Dublin, Ireland; ${ }^{2}$ Dublin City University, Dublin, Ireland

Background: Intra-articular corticosteroid injections (IACl) are frequently used in the medical management for children with juvenile idiopathic arthritis (JIA) as they allow treatment to be administered directly into a specific inflamed joint which may negate the requirement for further systemic medication or provide an adjuvant to them (1). However IACls are often associated with significant pain and discomfort for children. Inhaled Entonox gas (50\% nitrous oxide and $50 \%$ oxygen) is widely used as an analgesic and anxiolytic agent to reduce pain and anxiety for a variety of painful procedural in children. Evidence from a variety of different procedures has shown it to be an effective, safe and patient acceptable form of analgesia for both adults and children (2). It is widely acknowledged that patient satisfaction questionnaires allow clinicians to acquire meaningful and essential information that identifies gaps in care and facilitates the development of effective action plans for quality improvement in healthcare (3).

Objectives: The objective of this study was to assess children with JIA level of satisfaction and acceptability of using inhaled Entonox for $\mathrm{IACl}$ in a pediatric day-care unit.

Methods: Between the years 2017 and 2018, Entonox gas was administered to 48 children with JIA for Intra-articular corticosteroid injections in Temple Street Childrens University Hospital. Following this procedure children were invited to complete a modified version of a previously validated questionnaire (4).

Results: Of the 48 children approached, 32 completed the questionnaire (response rate $=66.6 \%$ ). The respondents ranged in age from 7-17 years and for $22(69 \%)$ of the children it was their first time having an IACI. While $25 \%$ of respondents reported being nervous or scared before the procedure, $100 \%$ of the children who completed the questionnaire reported that if they required another $\mathrm{IACl}$ in the future they would like to use Entonox again.

Conclusion: Overall satisfaction was high with all children reporting that they would be willing to use Entonox again if required. Furthermore satisfaction with the care provided by the clinicians was also rated very highly.

\section{REFERENCES}

[1] Casado R, Lumbreras J, De Inocencio J, Remesal A, Merino R. GarciaCconsueqra. Sedation for intra-articular corticosteroid injections in juvenile idiopathic arthritis: the views of patients and their parents. Eur J Pediatrics. 2013; $172: 14113$.

[2] Young A, Ismail M, Papatsoris AG, Barua JM, Calleary JG, Masood J. Entonox inhalation to reduce pain in common diagnostic and therapeutic outpatient urological procedures: a review of the evidence. Ann R Coll Surg Engl. 2012; 94(1):81.

[3] Al-Abri R, Al-Balushi A. Patient satisfaction survey as a tool towards quality improvement. Oman Med J. 2014; 29(1):37.

[4] Lew, VK, Lalwani, K, Palermo, TM Factors affecting parental satisfaction following pediatric procedural sedation. J Clin Anesth. (2010). 222934.

Acknowledgement: We wish to thanks all our colleagues in Temple Street Children's University Hospital and Dublin City University for their support and assistance in completing this project.

Disclosure of Interests: Norma O'Keeffe Consultant for: Norvatis, Speakers bureau: Abbvie, Clodagh Lowry: None declared, veronica lambert: None declared, Maeve Muldoon: None declared

DOI: 10.1136/annrheumdis-2019-eular.8287 